\title{
EDUCAÇÃO PERMANENTE COM AGENTES COMUNITÁRIOS DE SAÚDE: UMA PROPOSTA DE CUIDADO COM CRIANÇAS ASMÁTICAS
}

\author{
CONTINUING EDUCATION WITH COMMUNITY HEALTH AGENTS: A PROPOSAL FOR CARE OF \\ ASTHMATIC CHILDREN
}

\author{
Maria Wanderleya de Lavor Coriolano ${ }^{1}$ \\ Marinus de Moraes Lima ${ }^{2}$ \\ Bianca Arruda Manchester de Queiroga ${ }^{3}$ \\ Lídia Ruiz-Moreno ${ }^{4}$ \\ Luciane Soares de Lima ${ }^{5}$
}

Resumo O uso de metodologias ativas nos processos de formação dos trabalhadores de saúde é uma diretriz recomendada na Política Nacional de Educação Permanente em Saúde (PNEPS) para trabalhadores do Sistema Único de Saúde (SUS). Neste estudo, formulou-se uma intervenção educativa para agentes comunitários de saúde (ACS) sobre cuidados dirigidos a crianças/famílias com asma. O objetivo é descrever uma ação educativa com agentes comunitários de saúde sobre conhecimentos relacionados à asma, adotando as diretrizes da PNEPS no contexto da atenção primária. Trata-se de estudo 'quantiqualitativo', com avaliação pré-teste e pós-teste autopreenchida pelos agentes comunitários de saúde, além de metodologias ativas em três grupos focais vivenciais, que tiveram sua trajetória gravada e transcrita para posterior análise de dados, com uso da técnica análise de conteúdo na modalidade temática proposta por Bardin. Os conhecimentos dos ACS sobre mitos relacionados à asma apontaram acréscimo após a ação educativa. Dos grupos focais emergiram as temáticas: Educação em saúde para prevenção das doenças respiratórias; Significado atribuído à asma; Bombinhas: desmistificando conceitos; Fatores desencadeantes para asma; Adaptando cuidados preventivos; Avaliando os conhecimentos construídos. A utilização de metodologias ativas favoreceu o desenvolvimento de competências por parte dos ACS, despertando motivação na abordagem educativa junto às crianças/famílias com asma. Palavras-chave educação em saúde; asma; atenção primária à saúde; educação continuada; aprendizagem baseada em problemas.
Abstract The use of active methods in the health worker training process is a guideline that is recommended under the National Continuing Education in Health Policy (PNEPS) for National Health System (SUS) employees. In this study, the authors created an educational intervention for community health agents (CHA) regarding care aimed at children/families with asthma. The aim is to describe an educational action involving community health workers about asthmarelated knowledge, adopting the National Policy on Continuing Education in Health in the context of primary care. This was a 'quanti-qualitative' study, with pretest and posttest assessments filled in by the community health workers themselves, in addition to active approaches in three experiential focus groups, which had their activities recorded and transcribed for later data analysis using the content analysis methodology in accordance with the thematic mode proposed by Bardin. The CHA's knowledge about the myths related to asthma increased after the educational activity. The following themes emerged from the focus groups: Health education for the prevention of respiratory diseases; Meaning attributed to asthma; Firecrackers: demystifying concepts; Trigger factors for asthma; Adapting preventive care; Assessing the knowledge built. The use of active methodologies favored the development of skills among the CHAs, arousing motivation in the educational approach with children/families with asthma.

Keywords health education; asthma; primary health care; continuing education; problem-based learning. 


\section{Educação em saúde: novas formas de intervenção sobre a realidade}

Os modelos educativos em saúde vêm sofrendo alterações ao longo do tempo, passando de um modelo pedagógico tradicional, baseado na exposição de conteúdos e prescrição comportamental - sem levar em conta os saberes existentes da clientela, as motivações, crenças culturais e necessidades da população, apresentando consequentemente resultados insatisfatórios do ponto de vista sanitário -, para um modelo baseado na interação entre educadoreducando, profissional-usuário. Neste modelo estão envolvidos os pressupostos da horizontalidade do cuidado, a humanização e a articulação entre os saberes científico e popular.

As práticas de educação em saúde têm focalizado historicamente as mudanças no comportamento do indivíduo numa perspectiva tecnicista. Nas práticas sanitárias brasileiras, o modelo de educação em saúde passou do tradicional na década de 1970, baseado nas orientações centradas na exposição do educador e imposição de padrões a serem seguidos, a um modelo pós-Reforma Sanitária, no qual foram sendo incorporados os princípios da humanização, a educação popular em saúde, advinda da pedagogia freiriana, e a emancipação do ser humano como sujeito histórico-cultural (Bógus, 2007).

Na visão de Paulo Freire, o ser humano deve ser concebido como um ser histórico, devendo preceder no processo ensino-aprendizagem uma reflexão que produza no educando a capacidade de provocar mudanças na sua realidade social, permitindo que o homem chegue a ser sujeito, construindo-se como pessoa, transformando o mundo e estabelecendo relações de reciprocidade com outros sujeitos e com o seu ambiente, construindo cultura e história (Behrens, 1999).

Tais pressupostos e ideias de Paulo Freire não ficaram restritos à pedagogia, mas foram incorporados por outras áreas do conhecimento, incluindo a saúde, com as reformas conceituais e práticas instituídas pela Reforma Sanitária e pelo movimento de institucionalização do Sistema Único de Saúde (SUS), no qual a relação entre profissionais de saúde e usuários precisa superar a imposição de comportamentos a serem adotados pelos indivíduos para uma relação dialógica, em que os usuários reflitam sobre suas condições de saúde e se repensem os melhores e mais adequados caminhos para modificar os seus padrões de saúde-doença, com base na reflexão, consciência e autonomia.

O modelo tradicional de ensino-aprendizagem é criticado por Paulo Freire como sendo educação bancária, tendo em vista que neste método o educador apenas deposita conhecimentos aos educandos e estes apenas os guardam e arquivam. Transpondo isto para a educação em saúde, o trabalhador dessa área atua no processo de ensino-aprendizagem como o detentor do conhecimento absoluto, sem consideração aos saberes dos usuários, 
que possuem o conhecimento popular (Miranda e Barroso, 2004). Segundo esta concepção, a educação em saúde é um instrumento de dominação e de responsabilização dos indivíduos pela redução dos riscos à sua saúde, não contribuindo para a consolidação da integralidade e para a promoção à saúde (Mendes et al., 2007).

Pereira, Vieira e Amâncio Filho (2011) abordam a relevância do diálogo como uma exigência existencial, sendo definido como o encontro em que se solidarizam e se articulam o refletir e o agir de sujeitos endereçados ao mundo a ser transformado e humanizado. Nesse âmbito, não se pode reduzir esse encontro a um ato de depositar ideias de um no outro, mas sim a um ato de criação responsável pela libertação dos homens.

Ante esse panorama e considerando-se a formação biologicista e flexneriana dos profissionais da saúde, que preconiza a superespecialização, o Ministério da Saúde lança em 2004 a Política Nacional de Educação Permanente em Saúde (PNEPS) do SUS visando à efetivação dos seus princípios. Esta iniciativa objetiva trabalhar com os profissionais de saúde, colocando o cotidiano da prática no processo de formação, levando-os à problematização, à reflexão para agir em prol da mudança em parceria com a comunidade, à transformação das práticas profissionais e da própria organização do trabalho, tomando como referência as necessidades de saúde das populações e a organização da gestão setorial, tendo em vista que as mudanças no processo de educar em saúde só poderiam ocorrer com um novo olhar dos profissionais que executam as atividades de educação em saúde (Ceccim, 2005; Brasil, 2004a; Nicoletto, 2008).

Dessa forma, a educação em saúde pode funcionar como instrumento de transformação social que coloca a cultura no centro de seu processo, possibilitando atuar sobre a representação da comunidade, para sobre ela agir. Nesse modelo busca-se propiciar aos profissionais e clientela os recursos para conhecer, compreender e agir na sociedade para que se emancipem. Um dos elementos fundamentais do método de Freire consiste em utilizar o saber anterior do educando como ponto de partida do processo pedagógico (Alvim, 2007; Meyer et al., 2006; Pereira, 2003).

A educação permanente em saúde propõe a agregação entre aprendizado, reflexão crítica sobre o trabalho, resolutividade da clínica e promoção da saúde coletiva (Brasil, 2004a). Esta tem como eixos norteadores a relação entre educação e trabalho, a mudança nas políticas de formação e nas práticas de saúde, a produção e a disseminação do conhecimento (Brasil, 2003).

A proposta de educação permanente foi desenvolvida como estratégia para se alcançar o desenvolvimento da relação entre o trabalho e a educação. Parte do pressuposto de que o conhecimento se origina na identificação das necessidades e na busca de solução para os problemas encontrados, sendo válidos na solução dos problemas tanto o conhecimento científico como o 
popular. Nessa perspectiva, a atividade do trabalhador pode ser o ponto de partida de seu saber real, determinando, dessa maneira, sua aprendizagem subsequente (Lopes et al., 2007).

Essa política objetiva uma educação contínua dos trabalhadores do SUS, tendo como ponto de partida o seu trabalho, o cotidiano de suas atividades, em que o aprender e o ensinar se incorporam ao cotidiano das organizações e ao trabalho, para por meio de situações encontradas em cada realidade serem problematizados os conteúdos, com base na reflexão, na criticidade e no agir em prol da mudança, retomando os conceitos da pedagogia de Freire (Brasil, 2003).

Na conjuntura da Estratégia Saúde da Família (ESF), esses conceitos precisam ser incorporados para promover uma prática educativa problematizadora e emancipatória, na qual o cliente seja concebido como um ser ativo que traz suas experiências provenientes dos demais subsistemas de cuidado à saúde.

Com a Estratégia Saúde da Família, a relação entre profissionais da equipe e usuários pode ser mais estreita pelos pressupostos de adscrição da clientela, territorialização, promoção à saúde e prevenção das doenças, em substituição ao modelo hospitalocêntrico, impondo aos profissionais de saúde conviverem com outros modelos ou sistemas de cuidado e se aproximarem deles, os quais incluem o familiar e o popular, com vistas a uma maior aproximação da lógica do cliente/usuário e de uma interface entre o profissional e o cliente (Boehs et al., 2007).

Considerando a atenção básica como um dos locais prioritários para o desenvolvimento das ações de promoção à saúde, tendo como instrumento a educação em saúde, esta se configura como um ambiente propício para a consolidação de ações educativas que abordem não somente o processo saúde-doença, mas conceitos de cidadania e participação comunitária.

Apesar do conhecido potencial da educação em saúde como prática de mobilização da comunidade, observa-se que os serviços de saúde têm dado pouca ênfase às ações educativas. Os motivos desse impasse devem-se às características culturais da população e dos profissionais que assistem à clientela, ao desestímulo, à infraestrutura precária, ao despreparo dos profissionais de saúde para atuar segundo esse enfoque, à falta de recursos didáticos, dentre outros aspectos (Albuquerque e Stotz, 2004; Melo, Santos e Trezza, 2005).

Aliadas a esse processo de educação permanente dos trabalhadores do SUS, têm sido propostas mudanças concomitantes na formação dos profissionais de saúde, por meio de metodologias ativas de ensino-aprendizagem, que superam o depósito e transferência de conhecimentos, tendo em vista que a utilização das metodologias ativas pode favorecer a atuação em relação aos usuários e à sociedade como um todo. 
A metodologia da problematização oferece subsídios para uma aprendizagem significativa por descoberta, valorizando o aprender a aprender, sendo os conteúdos trabalhados na forma de problemas, cujas relações são analisadas e interpretadas, e o conhecimento é criado/recriado numa relação dialógica entre educandos e educadores, em um movimento tensionador entre o saber anterior e a experiência presente (Cyrino e Pereira, 2004; Berbel, 1998; Ceccim, 2008).

Transpondo esses conceitos para a educação em saúde, verifica-se similarmente que as metodologias ativas de ensino-aprendizagem deverão levar em conta os conhecimentos prévios dos usuários, a sua cultura, a disposição para aprender e a abertura interior para modificar a sua realidade, sendo necessária, além da própria formação dos profissionais de saúde, a abertura de canais de comunicação com os gestores dos sistemas locais de saúde para dispor de tempo e espaços apropriados para tais atividades, as quais demandam tempo, recursos humanos, motivação dos sujeitos envolvidos e continuidade para a produção de resultados a curto, médio e longo prazos.

Assim, as mudanças no sistema de saúde brasileiro baseadas em princípios de integralidade, equidade, participação popular, priorização da promoção à saúde, sem prejuízo das ações assistenciais, tem como política a priorização da atenção primária à saúde, organizada com base em equipes multiprofissionais, que deem conta das necessidades da clientela (Brasil, 2000).

Nessas equipes, destaca-se a figura do agente comunitário de saúde (ACS) como elo entre a comunidade e o sistema local de saúde, sendo uma pessoa que intermedeia as necessidades nesta área da comunidade com a demanda dos serviços locais (Silva e Dalmaso, 2002).

Estudo desenvolvido sobre o ACS para a avaliação da melhoria da qualidade na atenção básica (Qualis/PSF), no município de São Paulo, identificou que esse ator social não dispõe de instrumentos de tecnologia, incluídos aí os saberes para as diferentes dimensões esperadas do seu trabalho. Essa insuficiência faz com que ele acabe trabalhando com o senso comum, religião e, mais raramente, com os saberes e recursos das famílias e da comunidade (Silva e Dalmaso, 2002).

Evidencia-se na maioria das regiões do país que os ACS iniciaram seus trabalhos sem formação específica, receberam informações básicas sobre o que coletar em suas visitas e aprendem no cotidiano do seu trabalho o aprender-fazendo, dependendo do julgamento pessoal.

No que se refere à qualificação, verifica-se também que esse profissional não tem contado com ferramentas de ensino-aprendizagem que aliem o conhecimento popular trazido da comunidade com o conhecimento técnico-científico, indispensável para a apropriação de práticas de promoção à saúde.

Por esse prisma, vislumbra-se o uso de metodologias ativas nos processos de formação dos trabalhadores de saúde, e neste estudo formulou-se uma 
ação educativa com ACS sobre cuidados preventivos para crianças com asma, tendo em vista as potencialidades dessas metodologias para a construção de conhecimentos que subsidiem uma prática educativa continuada e mobilizadora junto às famílias que convivem com essa problemática, com condições de vida precárias que dificultam o alcance de tecnologias de alto custo.

O objetivo deste artigo foi descrever uma ação educativa com agentes comunitários de saúde sobre conhecimentos e práticas relacionados ao cuidado da criança asmática no domicílio, adotando as diretrizes da Política Nacional de Educação Permanente em Saúde no contexto da atenção primária.

\section{Aspectos metodológicos}

Trata-se de um estudo 'quantiqualitativo', 6 realizado com base em uma ação educativa, que abordou 'cuidados em asma' para agentes comunitários de saúde, adotando os pressupostos da Política Nacional de Educação Permanente em Saúde para trabalhadores do SUS. Foi desenvolvida no período de março a maio de 2009, com a perspectiva de produzir mudanças no contexto de vida das famílias sob responsabilidade desse trabalhador de saúde no município de Iguatu (Ceará).

O município de Iguatu está localizado na região centro-sul do estado do Ceará, distante $378 \mathrm{~km}$ da capital, Fortaleza, e tem uma população de 92.260 habitantes e 25 Equipes de Saúde da Família (ESF).

Participaram do estudo 34 agentes comunitários de saúde, trabalhadores de três Equipes de Saúde da Família, com condições de vida semelhantes.

Como instrumentos para a coleta de dados, utilizou-se uma avaliação objetiva pré-teste, autopreenchida pelos participantes do estudo antes da ação educativa, a qual abordava variáveis biológicas (sexo, idade), socioeconômicas e demográficas (renda familiar, escolaridade, tempo de trabalho), conhecimentos sobre mitos relacionados à asma. Após a ação educativa, realizou-se uma avaliação pós-teste, com perguntas sobre mitos relacionados à asma.

Na avaliação pré-teste, preencheram o instrumento 32 participantes; dois trabalhadores estavam no período de férias. No pós-teste, da mesma forma, outros dois trabalhadores estavam no período de férias. Assim, apenas trinta participantes preencheram as avaliações pré e pós-teste.

$\mathrm{Na}$ ação educativa, foram realizados três grupos focais vivenciais (um composto por dez participantes e os outros dois com 12 participantes), sendo realizados cinco encontros com cada grupo. 
O grupo focal vivencial é definido como uma técnica de pesquisa que coleta dados por meio das interações grupais ao se discutir um tópico especial sugerido pelo pesquisador. Como técnica, ocupa uma posição intermediária entre a observação participante e as entrevistas em profundidade. Pode ser caracterizado também como um recurso para compreender o processo de construção das percepções, atitudes e representações sociais de grupos humanos (Gondim, 2002).

Na condução dos grupos focais, foram utilizadas a metodologia da problematização e a aprendizagem baseada em problemas. Essas metodologias trabalham com problemas da realidade dos educandos ou problemas fictícios, os quais objetivam a abordagem de conteúdos significativos. Ambas propõem um conhecimento voltado para a reflexão e para mudanças do contexto no qual se atua.

O arco de Maguerez (Berbel, 1998) conduziu a organização dos conteúdos abordados, tendo em vista que a realidade de trabalho dos ACS, com seus conhecimentos prévios, constituiu o ponto de partida para a ação educativa, com a finalização na proposição de orientações sobre cuidados ambientais aplicáveis à realidade das crianças asmáticas e suas famílias.

Os dados quantitativos relacionados ao perfil biológico, socioeconômico e demográfico dos entrevistados e os conhecimentos sobre mitos relacionados à asma tiveram uma abordagem descritiva. A análise dos dados qualitativos foi realizada utilizando-se a técnica de codificação dos conteúdos das falas dos participantes, proposta por Bardin (Campus e Turato, 2009).

Os participantes assinaram um termo de consentimento livre e esclarecido. A pesquisa foi aprovada pelo Comitê de Ética e Pesquisa da Universidade Federal de Pernambuco.

\section{Resultados e discussão}

\section{Caracterização dos dados quantitativos}

Do total de 34 ACS, trinta participaram da avaliação pré-teste e pós-teste.

Na Tabela 1, estão descritas as características gerais dos agentes comunitários de saúde das três Unidades de Saúde da Família no município de Iguatu (Ceará). 
Tabela 1

Características gerais dos agentes comunitários de saúde de três Unidades de Saúde da Família $(\mathrm{N}=30)$ - Iguatu (Ceará), 2009

\begin{tabular}{|c|c|c|c|}
\hline Variáveis & $\mathrm{N}(\%)$ & Média & DP \\
\hline \multicolumn{4}{|l|}{ Idade (anos) } \\
\hline $20-30$ & $13(43,3 \%)$ & 35,27 & 9,77 \\
\hline $30-40$ & $7(23,3 \%)$ & & \\
\hline$>40$ & $10(3,33 \%)$ & & \\
\hline \multicolumn{4}{|l|}{ Sexo } \\
\hline Masculino & $1(3,3 \%)$ & & \\
\hline Feminino & $29(96,7 \%)$ & & \\
\hline \multicolumn{4}{|c|}{ Escolaridade (anos) } \\
\hline 7 a 11 & $27(90 \%)$ & & \\
\hline$>11$ & $3(10 \%)$ & & \\
\hline \multicolumn{4}{|c|}{ Tempo de trabalho (anos) } \\
\hline$=2$ & $14(46,7 \%)$ & & \\
\hline$>2$ & $16(53,3 \%)$ & & \\
\hline Renda familiar & & 712,33 & 364,08 \\
\hline
\end{tabular}

Verifica-se que a faixa etária predominante foi a de adultos jovens de 20-30 anos (13-43,3\%). Do mesmo modo, o gênero predominante foi o feminino, com 29 participantes $(96,7 \%)$; apenas um era do sexo masculino $(3,3 \%)$. Quanto à escolaridade, a maioria, 27 (90\%), tinha 11 anos de estudo, sendo esta a escolaridade exigida para o desempenho das atividades de agente comunitário de saúde, e três (10\%) estavam participando de cursos de nível superior. Quanto ao tempo de trabalho, os que trabalhavam há mais de dois anos apresentavam uma discreta maioria - $16(53,3 \%)$ versus $14(46,7 \%)$-, fato atribuído à ampliação do número de agentes comunitários no ano anterior pelo município.

Imperatori e Lopes (2009) encontraram resultados semelhantes no que se refere ao perfil dos ACS, constatando que a maioria dos agentes era do sexo feminino. Predominou, nesse caso, a faixa etária dos 21 aos 30 anos para 14 deles, sendo que a faixa etária de 21 a 40 reuniu 22 ACS, o que correspondeu a $61,1 \%$ do total dos entrevistados.

Nos últimos anos, constata-se que os ACS que ingressam no Programa de Agentes Comunitários de Saúde (Pacs) são mais jovens, selecionados por critérios como maior escolaridade e qualificação, sendo, dessa forma, mais bem classificados nos processos seletivos para a função. 
Pode-se dizer que esse perfil aproxima-se daquele encontrado para os trabalhadores da saúde de forma geral. O trabalho de ACS engaja mais mulheres, sugerindo a adequação de gênero ao tipo de atividade. A ação próxima às famílias e a habilidade advinda do processo de socialização feminino são elementos que justificam a presença e a seletividade de sexo/gênero nos processos de contratação para essa atividade (Imperatori e Lopes, 2009).

Na Tabela 2, são apresentados os conhecimentos dos agentes comunitários de saúde sobre mitos relacionados à asma antes e depois da ação educativa.

Tabela 2

Conhecimentos dos agentes comunitários sobre mitos relacionados à asma antes e após um programa educativo utilizando metodologias ativas - Iguatu (Ceará), 2009

\begin{tabular}{|c|c|c|c|c|c|}
\hline Variáveis & Antes (N) & $\%$ & Depois $(\mathrm{N})$ & $\%$ & $\mathbf{P}$ \\
\hline \multicolumn{6}{|l|}{ Asma mata? } \\
\hline Sim & 19 & 63,3 & 27 & 90,0 & 0,01 \\
\hline Não/Não sabe & 11 & 30,0 & 02 & 6,7 & \\
\hline \multicolumn{6}{|c|}{ Asma se pega na creche? } \\
\hline Sim & 07 & 23,3 & 04 & 13,3 & 0,13 \\
\hline Não & 01 & 56,7 & 26 & 86,7 & \\
\hline \multicolumn{6}{|c|}{ Asma se transmite? } \\
\hline Sim & 05 & 16,7 & 04 & 13,3 & 0,40 \\
\hline Não & 21 & 70,0 & 26 & 86,7 & \\
\hline \multicolumn{6}{|c|}{$\begin{array}{l}\text { Asma se pega com } \\
\text { alimentos gelados? }\end{array}$} \\
\hline Sim & 07 & 23,3 & 01 & 3,3 & 0,008 \\
\hline Não & 16 & 53,3 & 29 & 96,7 & \\
\hline
\end{tabular}

Fonte: Os autores.

Nota: P - medida de significância estatística.

Observou-se uma satisfatória aquisição de conhecimentos nas perguntas sobre mitos relacionados à asma, sendo relevante o fato de nenhum participante ter afirmado 'não saber' ao final da ação educativa. Isso demonstra a participação efetiva dos agentes comunitários de saúde nos encontros realizados com as discussões propostas sobre os aspectos que envolvem a asma em crianças, bem como a relevância de ações educativas preventivas que enfoquem o controle ambiental de alérgenos nos domicílios visitados pelos agentes comunitários. Os participantes puderam verbalizar ao longo dos encontros o interesse pelo tema, tendo em vista que não tinham anteriormente participado de nenhuma ação educativa que abordasse essa temática. 
Em estudo de Andrade et al. (2008), realizou-se uma intervenção na modalidade de jogo educativo com ACS sobre doenças respiratórias infantis, o qual apresentou similarmente ao nosso estudo uma elevação no conhecimento dos ACS, revelada nos testes pré e pós-intervenção educativa, apontando que o processo de construção do conhecimento, junto a agentes comunitários de saúde, demonstrou ser eficaz e satisfatório, atendendo às demandas de educação em saúde relacionada ao atual contexto dos serviços de saúde.

A avaliação pré e pós-teste do nosso estudo, que relacionou os conhecimentos dos ACS sobre mitos associados à asma, demonstra um ganho satisfatório de conhecimentos após a ação educativa, sendo preponderante, além desse ganho de conhecimentos, o desenvolvimento de competências observadas com base na análise qualitativa, que será detalhada a seguir.

\section{Caracterização dos dados quantitativos}

Durante a ação educativa, os educandos eram instigados a construir o conhecimento mediante problemas existentes na sua realidade e problemas fictícios elaborados pela pesquisadora, com o objetivo de abordar conteúdos significativos. Nesses momentos, os educandos expressavam saberes anteriores e saberes adquiridos durante o processo ensino-aprendizagem, num movimento tensionador de construção/reconstrução de conhecimentos e práticas, com o objetivo de transformar a realidade das crianças/famílias asmáticas nas microáreas de atuação.

Com a utilização da análise de conteúdo proposta por Bardin, elaboraram-se os temas descritos a seguir.

\section{Tema 1. Educação em saúde para prevenção das doenças respiratórias}

Nos discursos dos ACS, verifica-se que alguns já realizavam algumas orientações para a prevenção das doenças respiratórias para as famílias sob riscos ambientais. A esse respeito, o Agente 1 relata:

(...) ela faz fogo dentro de casa, a criança cansada, a casa bem baixinha, cheia de teia de aranha, ela não cuida. Eu ia olhar como era o sistema, de matar muriçoca, queimar pano, ia orientar: não faça fogo, quando for espanar tire a criança pra fora, mesmo sabendo que a maior parte ela não faz (Agente 1).

Observa-se que as questões educativas são complexas, e a adoção ou não de tais medidas por parte das famílias deixa os ACS conscientes da escassa eficácia da ação educativa desenvolvida por eles. A fala de A-15 ilustra como a relação entre o ACS e o usuário pode estar centralizada no 
discurso unidirecional e prescritivo, no qual o trabalhador de saúde dita as normas e padrões a serem seguidos, enquanto ao usuário cabe apenas a assimilação da informação e a mudança no seu comportamento.

Com relação às orientações que eu dou de pedir pra botar o carvão pra fora, de evitar fumaça, a questão dos fumantes, pra não fumarem dentro de casa, o ventilador, porque tem gente que diz: “Ah, eu só durmo se for com o ventilador ligado", a casa imunda, cheia de poeira, aí quer dizer, eu tenho feito isso, tenho encaminhado pro PSF e dado essas orientações, sempre falo, mas eles não aprenderam ainda não (A-15).

Como vemos nos depoimentos mencionados, há ainda uma certa culpabilização do usuário que, na visão do ACS, não aprende e por conseguinte não executa a norma ditada pelo trabalhador de saúde. Essa concepção leva a questionamentos sobre como vêm se processando as práticas educativas na interação entre o trabalhador e o usuário no contexto do Sistema Único de Saúde. As ações educativas têm privilegiado o conhecimento científico em detrimento do conhecimento popular? O conhecimento dos usuários tem sido valorizado pelo ACS, que pertence à mesma comunidade e cultura, ou o saber 'verdadeiro' dos serviços de saúde é imposto à população?

Uma questão que emerge é quanto ao método de tais orientações centradas apenas na prescrição comportamental, sem a problematização com os sujeitos sociais, o que pode dificultar a incorporação dos ensinamentos por parte das famílias.

Em situações como as mencionadas, a autoestima do ACS como produtor de mudanças nas famílias poderá ficar comprometida, e este poderá apresentar desestímulo diante da sua função de orientar as famílias nas condições relacionadas à saúde-doença.

As práticas educativas desenvolvidas para ensinar à comunidade o autocuidado e a adoção de estilos de vida saudáveis têm produzido uma normatização na vida das pessoas que muitas vezes gera conflitos e resistências na aceitação de tais orientações. Sabe-se que o ato de fala por si não implica necessariamente mudanças no modo de os sujeitos envolvidos modificarem seus comportamentos (Ferreira et al., 2009).

Um dos pontos que têm recebido críticas no que se refere à posição de mediação entre os profissionais da equipe e a comunidade é o risco de o ACS, no processo de educação com clientes e famílias, assimilar o discurso dos técnicos e reproduzi-lo de forma mecânica e acrítica para os usuários (Bornstein e Stotz, 2008).

Novas competências são requeridas para os profissionais da saúde no sentido de superar a formação técnico-cientificista que deixa de potencializar as inter-relações desenvolvidas entre profissionais e usuários (Ciuffo e Ribeiro, 2008). 
As mudanças desejadas envolvem necessariamente iniciativas sobre os processos de formação permanente da área da saúde que considerem a perspectiva dos sujeitos participantes gerando aprendizagens significativas.

\section{Tema 2. Significado atribuído à asma}

Durante a ação educativa, foi relevante conhecer o significado que os ACS atribuíam à asma, valorizando seus saberes prévios, antes da discussão dos conceitos relacionados à doença.

Das discussões produzidas, emergiu a dualidade dos conceitos de asma e bronquite, com seus significados para os ACS. Para A-16 e A-3, a asma aparece como uma doença grave, associada à morte, remetendo ao medo no imaginário da população, enquanto o termo bronquite é entendido como uma afecção mais leve e de menor impacto.

Eu acho que asma não é a mesma coisa que bronquite alérgica, não, asma é um piado, eu nunca vi, mas minha mãe conta que a pessoa fica pra morrer, é uma coisa muito feia, e bronquite alérgica a criança cansa (A-16).

Asma pesa mais, eu acho que pra mãe ouvir que é asma é mais avassalador porque as pediatra diz pra mãezinha que é leiga, elas não diz assim: “Oh, mãezinha, essa criança tem asma." Elas diz assim: “Oh, mãe, vamos tratar essa bronquite alérgica" (A-3).

Esse peso semântico que a asma possui parece não ser apenas para a comunidade, mas também para os ACS e até mesmo para os médicos, quando utilizam no seu diagnóstico o nome bronquite para orientar as mães quanto ao problema de saúde de seus filhos.

O fato de a asma ser considerada grave, contrapondo-se à simplicidade conferida à bronquite, apesar de ser um conforto para as mães quando lidam com o diagnóstico dos filhos, poderá ser responsável pela falta de adoção de medidas de cuidados ambientais e terapia medicamentosa continuada, a depender da gravidade do quadro, que devem ser realizadas a longo prazo, tendo em vista o caráter crônico da doença.

Por sua vez, o conflito entre os posicionamentos do ACS e do médico (responsável pelo diagnóstico da criança) poderá tensionar as relações na equipe de saúde e comprometer a relação de confiança entre o ACS e o usuário, embora numa perspectiva superadora do cientificismo seja necessário que o profissional da saúde tenha clareza dos conceitos e utilize a terminologia correta no sentido de garantir a adoção de medidas adequadas.

Na proposta educativa desenvolvida com os ACS, conteúdos que esclareciam a pertinência da utilização do termo asma ou bronquite foram 
abordados com uso de estratégias dialógicas e problematizadoras, já que o correto entendimento deve ser o alicerce das ações educativas em saúde.

É relevante dizer que a educação em asma necessita incorporar a educação permanente de todos os trabalhadores da ESF e, subsequentemente, pacientes e familiares, como foi recomendado desde o I Consenso Brasileiro de Educação em Asma (1996).

\section{Tema 3. Bombinhas: desmistificando conceitos}

A política nacional de atenção integral às pessoas com doenças respiratórias incorpora na atenção básica o manejo de duas principais afecções respiratórias crônicas (rinite alérgica e asma), uma vez que a abordagem a pessoas com estas doenças vem acontecendo somente nos quadros agudos, tendo como resultados internações desnecessárias, visitas frequentes a serviços de urgência e emergência, faltas à escola e ao trabalho, resultando em alta morbidade (Brasil, 2004b).

Nesse aspecto, os ACS apresentaram escassos conhecimentos no que tange à abordagem dessas doenças, quando eles poderiam estar atuando na abordagem educativa junto às mães sobre técnica de uso de dispositivos inalatórios e cuidados preventivos para espaçamento de crises, sendo necessária a incorporação dessa temática nos processos de formação e educação permanente para ACS.

Sobre essa temática, no início da ação educativa, A-17 menciona o despreparo para o uso de dispositivos inalatórios com um usuário de sua microárea, atribuindo importância ao conhecimento do ACS para orientação das famílias sob sua responsabilidade.

Uma pessoa da minha área tava com uma bombinha e aí eu nem soube falar nada.

Eu nunca tinha nem visto uma bombinha, eu nem sabia como usar (A-17).

No início da ação educativa, os ACS expressaram equívocos relacionados ao uso de medicação inalatória. Porém, durante o desenvolvimento da proposta educativa ficou evidente a aprendizagem sobre os procedimentos mais adequados para o paciente, como se observa na fala de A-2:

A questão da preferência pela inalação, pela rapidez, vai direto, menos efeitos colaterais, e eu achava que era o contrário, que dava mais efeito até pela taquicardia, eu achava que era um dos efeitos colaterais e que prejudicava o coração e não prejudica (A-2).

Esses conceitos equivocados provavelmente podem estar presentes na comunidade em geral e poderão prejudicar a adesão a essa terapêutica por 
familiares de crianças que necessitam do uso de tais dispositivos. O despreparo de profissionais que lidam diretamente com essa clientela também contribui para o uso inadequado da medicação inalatória.

Em estudo realizado em Minas Gerais, abordando os conhecimentos de pacientes asmáticos sobre a doença, foi encontrado que pouco mais da metade da amostra fazia uso de medicamentos (55\%). Entretanto, quando solicitou-se uma demonstração quanto ao uso da medicação inalatória (bombinhas), foram observados erros nos procedimentos e desconhecimento em relação aos efeitos colaterais (Vieira, Silva e Oliveira, 2008).

Aprender a técnica de uso dos dispositivos inalatórios é relativamente fácil quando se demonstra exaustivamente a técnica, levando em conta os diversos fatores envolvidos, tais como coordenação dos movimentos inspiratórios e expiratórios, coordenação motora, destreza manual para acionar o dispositivo, sendo obtido um acréscimo de $36,4 \%$ para $86,4 \%$ em um programa de educação realizado pela enfermagem com pacientes asmáticos (Bettencourt et al., 2002).

Tendo em vista o protagonismo do ACS junto às famílias como orientador e educador em saúde, os conhecimentos adquiridos quanto ao uso das bombinhas mostra-se de extrema relevância para auxiliar as crianças/famílias sob seus cuidados, auxiliando-as para o uso adequado, com desmistificação de conceitos que poderão prejudicar a adesão ao tratamento.

Nesse âmbito, essa ação educativa está consoante com as premissas que regem a Política Nacional de Educação Permanente em Saúde para trabalhadores do SUS, uma vez que esta propõe que os processos de capacitação dos trabalhadores da saúde tomem como referência as necessidades de saúde das pessoas, tendo como objetivos a transformação das práticas profissionais e a organização do processo de trabalho (Brasil, 2003).

\section{Tema 4. Fatores desencadeantes para asma}

Um dos conteúdos abordados durante a ação educativa foi o reconhecimento de fatores desencadeantes nos domicílios, o qual consistiu em apresentação de uma situação problema, discussões do grupo com explicações e hipóteses de solução, leitura de textos pertinentes ao assunto. Como atividade adicional, a dispersão dos participantes em visitas domiciliares, visando à identificação desses fatores nas famílias que tinham crianças asmáticas.

O reconhecimento de fatores desencadeantes no ambiente domiciliar constitui o passo inicial para a implementação de medidas preventivas. Durante a atividade de dispersão, os educandos puderam constatar vários fatores desencadeantes, como descritos por A-18: 
Tinha brinquedos de pelúcia e um animalzinho, um cachorrinho, aí ela [mãe] disse que teve que doar, pensando na filha, também porque fazia mal. Aí eu disse: “É, realmente não é bom ter nem urso de pelúcia nem animais domésticos dentro de casa, por conta desse problema" (A-18).

Nesse diálogo, o ACS demonstra uma competência para escuta e valorização da informação correta manifestada pela mãe. Além disso, a estratégia desenvolvida na proposta educativa propiciou ao ACS perceber a importância do controle ambiental de alérgenos e sensibilizantes como componente primordial do tratamento, na medida em que a menor exposição aos alérgenos pode contribuir para a redução dos fenômenos inflamatórios.

Os fatores alérgicos ocupam lugar de destaque na manutenção dos fenômenos inflamatórios brônquicos. A redução da carga alergênica, de ácaros em particular, auxilia na redução da intensidade da sintomatologia e da hiperresponsividade brônquica; baseia-se, por um lado, na diminuição da umidade relativa (por meio de aeração e insolação), e, por outro, na utilização de capas nos colchões e travesseiros, na remoção de tapetes e similares, cortinas e objetos acumuladores de poeira. O controle ambiental inclui o afastamento de animais domésticos, exclusão da população e circulação de baratas, mofo e tabagismo passivo (Moura, Camargos e Blic, 2002).

Mediante a problematização dos riscos ambientais existentes nos domicílios sob responsabilidade dos ACS, os educandos se voltaram para a realidade (observação da realidade), com o objetivo de identificação in loco dos fatores agravantes relacionados às crises asmáticas, constatando a presença de vários deles.

A percepção do ACS sobre situações problemáticas no seu cotidiano de trabalho está relacionada aos conhecimentos sobre determinado assunto e as experiências pessoais vivenciadas anteriormente. No que se refere às inadequações do domicílio, os ACS despertaram o senso crítico de observação e intervenção junto às famílias quando foram sensibilizados para a relevância do controle ambiental no tratamento da asma.

A educação permanente objetiva, assim, além da capacitação técnicocientífica, a capacidade de desenvolver competências em todas as relações do sujeito-educando com as situações do seu cotidiano de trabalho (Paschoal, Mantovani e Méier, 2007). A atuação do ACS com mais conhecimentos sobre temáticas que são relevantes para a saúde da população mostra-se como importante dispositivo para otimizar a qualidade de vida.

Para interagir no mundo da vida e do trabalho, é necessário inserir processos de reflexão crítica, para uma educação que destaque o desenvolvimento da autonomia e da criatividade no pensar, no sentir e no querer dos sujeitos sociais (Brasil, 2003). Em concordância com essa política, o objetivo do presente estudo foi desenvolver nos educandos a autonomia de 
construírem práticas educativas mais solidárias e horizontais com as famílias de crianças asmáticas sob sua responsabilidade.

\section{Tema 5. Adaptando cuidados preventivos}

Os cuidados ambientais nos domicílios de crianças asmáticas precisam ser adaptados à realidade das famílias de forma criativa e contextualizada. O ACS, ao representar o elo entre comunidade e os serviços de saúde, conhece a realidade das famílias e as condições econômicas que permitem a adesão ou não às recomendações.

Em todos os grupos focais, foi elaborado um roteiro pelos ACS para sistematização do seu processo de trabalho junto às famílias de crianças asmáticas. A esse respeito, ao final da ação educativa, A-15 menciona como foi a sua atuação em um domicílio em que residia uma criança asmática:

Relatamos os perigos para a saúde da criança, que asma pode levar à morte, explicamos como evitar as crises com hábitos mais saudáveis. A criança já esteve internada, e a mãe relata que não apresenta melhora, querendo mais remédio. Informamos que a medicação é importante, mas precisa muito da colaboração da mesma para evitar as crises constantes (A-15).

No entanto, percebe-se na fala do ACS um caráter transmissivo de informações com centralidade no profissional e ênfase nos aspectos técnicocientíficos. Verificou-se ao longo dessa ação educativa que, apesar da incorporação de conhecimentos significativos relacionados aos cuidados ambientais e aos mitos e crenças relativos à doença, a interação entre ACS e usuários poderá ficar comprometida, caso continuem sendo adotadas as orientações centradas na imposição de comportamentos e na valorização suprema do conhecimento técnico-científico com caráter transmissivo de informação. Assim, torna-se necessário instrumentalizar o ACS com ferramentas de trabalho que possibilitem uma prática educativa que tenha em conta os saberes dos usuários e os levem a problematizar o seu contexto de saúdedoença-cuidado.

No estudo de Maciel et al. (2009) em Fátima do Sul (Mato Grosso do Sul), foram pesquisadas as concepções de ACS sobre a educação em saúde. Os autores mencionam que, nos discursos dos ACS, estes veem o profissional de saúde como detentor do conhecimento biomédico sobre temas que envolvem o processo saúde-doença, e assim há riscos de se adotarem medidas educativas impositivas. Em nome desse saber validado cientificamente, muitas vezes considerado como verdadeiro, único e absoluto, se delimita o que é considerado melhor para as pessoas, sem propiciar o fortalecimento dos usuários e das famílias (Maciel et al., 2009). 
Compartilhamos da opinião de Shimizu e Rosales (2009) de que há a necessidade de adoção de estratégias comunicacionais dialógicas, que permitam conhecer o indivíduo, incluindo as suas crenças, valores e as condições objetivas em que vive. Essa forma de abordagem parte do suposto de que o usuário é portador de um saber diverso do saber técnico, mas que deve ser valorizado, a fim de promovê-lo à autonomia de decidir de forma consciente sobre as estratégias para promover, manter e recuperar a sua saúde.

\section{Tema 6. Avaliando os conhecimentos construídos}

No final da ação educativa, os participantes foram instigados a avaliar a metodologia empregada na abordagem dos conteúdos relacionados aos cuidados ambientais em asma. A esse respeito, A-10 ressalta a importância de se considerar nos processos de educação permanente o cotidiano do trabalhador de saúde para a abordagem dos conteúdos, de forma que o conhecimento apreendido possa ter aplicabilidade e efetividade.

Quanto ao aprendizado, adorei, porque a gente vai colocando em prática, e na nossa convivência com as famílias, você vai logo observar, eu já fiz um curso sobre iras (infecções respiratórias agudas), mas faz muito tempo (A-10).

Outro ponto relevante é o reconhecimento da alta prevalência da asma na comunidade, fato que passava despercebido pelos sujeitos do estudo, que a partir da ação educativa passam a ter um olhar mais abrangente sobre esse relevante problema de saúde, que produz impactos de morbidade e mortalidade em nosso meio, como ressaltado por A-11.

Eu tinha na minha área bastante crianças com esse problema e eu num sabia o que fazer, mas não sabia total o cuidado necessário e foi de grande ajuda, vou levar essas informações que você trouxe pra mim, pra minha área, o que eu fico triste é que foi pouco tempo (A-11).

A demanda por participar de experiências formativas foi expressa pelo ACS ao final de sua fala, o que condiz com o desejo de maior autonomia e profissionalização no trabalho que extrapolem a prática restrita à execução de tarefas segundo regras definidas (Mendonça, 2004).

Observa-se a grande potencialidade de metodologias ativas para o desenvolvimento do aprendizado de conteúdos, gerando motivação nos participantes, interesse diante das novas descobertas apreendidas a cada dia, possibilidade de aplicação do aprendizado ao contexto de trabalho, além da motivação em serem considerados como principais sujeitos do processo ensino-aprendizagem, assumindo o educador um papel de facilitador do processo. 
Entretanto, apesar de vivenciarem uma experiência diferenciada no que se refere ao processo de ensino-aprendizagem, os relatos dos informantes ainda carregam marcas da educação em saúde como repasse de informações, no qual o profissional é detentor do conhecimento científico hegemônico e o usuário porta um saber desconsiderado na relação dialógica entre o profissional e o usuário.

A questão da gente aprender e repassar pra comunidade, claro que não é $100 \%$, mas pelo menos algumas pessoas que a gente repassar, aprender e fazer em casa e repassar pra outras pessoas, pode melhorar a vida até de uma comunidade inteira (A-15).

Leonello e Oliveira (2008) chamam a atenção para o fato de a supervalorização do conhecimento científico contribuir para uma atenção fragmentada e voltada predominantemente para as demandas dos profissionais e serviços de saúde em vez de para as necessidades do indivíduo assistido.

A problematização busca, portanto, romper com essa dicotomia, agregando os saberes do senso comum, trazidos pelo ACS como pertencentes à comunidade, aos saberes técnico-científicos, propondo a interação posterior nessa direção para os agentes comunitários de saúde e a população assistida.

\section{Considerações finais}

A expansão da Estratégia Saúde da Família põe em destaque o ACS como ator social importante na viabilização dessa política de saúde. Esse destaque evidencia a necessidade de se desenvolverem estudos sobre seu perfil ocupacional, social e processo de formação profissional.

O perfil dos ACS participantes deste estudo mostrou maioria de adultos jovens, do sexo feminino, com ensino fundamental completo, sendo que alguns já estavam inseridos no ensino superior no momento da pesquisa. Tal perfil condiz com a maior escolaridade e profissionalização também observada por outros autores. Essa tendência suscita questões para melhor compreensão do papel do ACS em termos de desempenho profissional - o fato de não ser exigida uma formação específica oferecida por instituições reconhecidas faz com que seu trabalho seja fortemente condicionado pelo contexto. Ele é percebido como integrante da comunidade e interlocutor entre esta e os demais profissionais da equipe, porém pouco identificado com ações de educação em saúde. O desenvolvimento de processos formativos no sentido de ampliar a autonomia e o papel educador do ACS tornase imperioso no processo de construção de sua identidade profissional.

A ação educativa com agentes comunitários de saúde abordando os cuidados preventivos em asma mostra-se como uma proposta inovadora de 
educação permanente dos trabalhadores do SUS, sendo a asma e a rinite temas que não vêm sendo enfatizados pelos serviços de saúde, existindo apenas alguns programas pontuais que têm desenvolvido atividades de prevenção na atenção básica.

No presente estudo, constatou-se com base nos dados quantitativos e qualitativos um desenvolvimento de competências conceituais e atitudinais relacionadas ao cuidado de famílias/crianças com diagnóstico de asma. Os agentes comunitários de saúde obtiveram um acréscimo importante de conhecimentos relacionados à asma e cuidados preventivos a serem vivenciados pelas famílias que convivem com essa problemática.

A utilização da metodologia da problematização constituiu estratégia potencial para o desenvolvimento do compromisso por parte dos ACS, despertando motivação para compartilhar os conhecimentos construídos com as crianças/famílias com asma. Embora o ACS tenha desenvolvido durante a ação educativa uma percepção ampliada dos possíveis fatores desencadeantes presentes nos domicílios, foi possível identificar nas falas que a interação ACS-usuário, durante a dispersão, ainda apresenta um caráter transmissivo e prescritivo.

Esses achados reforçam a necessidade de se considerarem, nas ações de educação permanente desses trabalhadores, estratégias que possibilitem o desenvolvimento de competências procedimentais relacionadas às práticas educativas desenvolvidas na comunidade.

A aquisição de saberes por parte dos educandos buscou a construção de um conhecimento aplicável à realidade do trabalho desses sujeitos na sua interação com as famílias, apresentando como limitações o curto tempo para a execução da ação educativa.

Aponta-se a necessidade de incorporação de atividades semelhantes com a participação dos demais membros da equipe da Estratégia Saúde da Família, adotando metodologias ativas que valorizem os saberes prévios dos educandos, objetivando dessa forma práticas de educação permanente problematizadoras com monitorização pela equipe de saúde local, e em particular pelo enfermeiro, que é considerado o profissional responsável pela educação permanente e pelo acompanhamento das atividades dos agentes comunitários de saúde.

Sugere-se que estudos posteriores focalizem as práticas educativas e comunicativas que vêm se efetivando entre os trabalhadores de saúde e usuários, tendo em vista que os resultados apontam para uma prática educativa prescritiva, destoante dos princípios e premissas propostos pela Estratégia Saúde da Família, a qual propõe a necessidade de vínculos, corresponsabilização e horizontalidade do cuidado em saúde. 


\section{Colaboradores}

Maria Wanderleya de Lavor Coriolano participou da concepção, coleta de dados, análise de dados e redação do artigo. Marinus de Moraes Lima e Bianca Arruda Manchester de Queiroga colaboraram na revisão. Lidia RuizMoreno participou da redação e revisão final. Luciane Soares de Lima atuou na concepção, orientação, redação do artigo e revisão.

\section{Notas}

1 Professora substituta do Departamento de Enfermagem da Universidade Federal de Pernambuco (UFPE), Recife, Pernambuco, Brasil. Doutoranda em Saúde da Criança e do Adolescente pela Universidade Federal de Pernambuco (UFPE). <wandenf@yahoo.com.br> Correspondência: Rua Pereira de Miranda, 1.075, apto. 1701, Papicu, CEP 60175-045, Fortaleza, Ceará, Brasil. <wandenf@yahoo.com.br>

2 Médico do Hospital Geral de Fortaleza, Fortaleza, Ceará, Brasil. Mestrando em Farmacologia pela Universidade Federal do Ceará (UFC). <marinuslima@yahoo.com.br>

3 Professora do Departamento de Fonoaudiologia e da Pós-Graduação em Saúde da Criança e do Adolescente da Universidade Federal de Pernambuco (UFPE), Recife, Pernambuco, Brasil. Doutora em Psicologia Cognitiva pela Universidade Federal de Pernambuco (UFPE). <queiroga.bianca@gmail.com>

4 Professora adjunta do Centro de Desenvolvimento do Ensino Superior em Saúde e da Pós-Graduação em Ensino em Ciências da Saúde da Universidade Federal de São Paulo (Unifesp), São Paulo, SP, Brasil.<lidia.ruiz@unifesp.br>

5 Professora titular do Departamento de Enfermagem e da Pós-Graduação em Saúde da Criança e do Adolescente da Universidade Federal de Pernambuco (UFPE), Recife, Pernambuco, Brasil. Pós-doutora em Enfermagem pela Universidade Federal de São Paulo (Unifesp). <luciane.lima@globo.com>

6 Resultado da dissertação de mestrado Repercussão de uma intervenção educativa com agentes comunitários de saúde nas condições ambientais de domicílios de crianças asmáticas, defendida no Mestrado em Saúde da Criança e do Adolescente, da UFPE, em 2010. 


\section{Referências}

ALBUQUERQUE, Paulette Cavalcanti; STOTZ, Eduardo Navarro. A educação popular na atenção básica à saúde no município: em busca da integralidade. Interface - Comunicação, Saúde, Educação, Botucatu, v. 8, n. 15, p. 259-274, 2004.

ALVIM, Neide Aparecida Titonelli; FERREIRA, Márcia de Assunção. Perspectiva problematizadora da educação popular em saúde e a enfermagem. Texto e Contexto Enfermagem, Florianópolis, v. 16, n. 2, p. 315319, 2007.

ANDRADE, Raquel Dully et al. Jogo educativo: capacitação de agentes comunitários de saúde sobre doenças respiratórias infantis. Acta Paulista de Enfermagem, São Paulo, v. 21, n. 3, p. 444-448, 2008.

BEHRENS, Marilda Aparecida. A prática pedagógica e o desafio do paradigma emergente. Revista Brasileira de Estudos Pedagógicos, Brasília, v. 80, n. 196, p. 383-403, 1999.

BERBEL, Neusi Aparecida Navas. A problematização e a aprendizagem baseada em problemas: diferentes termos ou diferentes caminhos? Interface - Comunicação, Saúde, Educação, Botucatu, p. 139-154, 1998.

BeTtencourt, Ana Rita de Cássia et al. Educação de pacientes com asma: atuação do enfermeiro. Jornal de Pneumologia, São Paulo, v. 28, n. 4, p. 193-200, 2002.

BOEHS, Astrid Eggert et al. A interface necessária entre enfermagem, educação em saúde e o conceito de cultura. Texto e Contexto Enfermagem, Florianópolis, v. 16, n. 2, p. 307-314, 2007.

BÓGUS, Cláudia Maria. A educação popular em saúde como possibilidade para o incremento do controle social no setor saúde. o Mundo da Saúde, São Paulo, v. 31, n. 3, p. 346-354, 2007.
BORNSTEIN, Vera Joana; STOTZ, Eduardo Navarro. Concepções que integram a formação e o processo de trabalho dos agentes comunitários de saúde: uma revisão da literatura. Ciência \& Saúde Coletiva, Rio de Janeiro, v. 13, n. 1, p. 259-268, 2008.

BRASIL. Ministério da Saúde. Sistema Único de Saúde: princípios e conquistas. Brasília, DF: Ministério da Saúde, 2000.

Política de Educação e Desenvolvimento para o SUS. Caminhos para a Educação Permanente em Saúde. Pólos de Educação Permanente em Saúde. Brasília, DF: Ministério da Saúde, 2003.

Portaria n. 198/GM/MS, de 13 de fevereiro de 2004. Institui a Política Nacional de Educação Permanente em Saúde como Estratégia do Sistema Único de Saúde para a formação e o desenvolvimento de trabalhadores para o setor e dá outras providências. Diário Oficial da União. Brasília, DF: Ministério da Saúde, 2004a.

Asma e rinite: linhas de conduta em atenção básica. Brasília: Ministério da Saúde, 2004b.

CAMPUS, Claudinei José Gomes; TURATO, Egberto Ribeiro. Análise de conteúdo em pesquisas que utilizam metodologia clínico qualitativa: aplicação e perspectivas. Revista Latino-Americana de Enfermagem [on line], Ribeirão Preto, v. 17, n. 2, 2009. Disponível em: <www.scielo.br/pdf/rlae/v17n2/pt_19. pdf>. Acesso em: 28 fev. 2012.

CECCIM, Ricardo Burg. Educação Permanente em Saúde: descentralização e disseminação da capacidade pedagógica na saúde. Ciência \& Saúde Coletiva, Rio de Janeiro, v. 10, n. 4, p. 975-986, 2005.

A emergência da educação e ensino da saúde: interseções e intersetorialidades. Ciência \& Saúde, Porto Alegre, v. 1, n. 1, p. 9-23, 2008. 
CIUFFO, Roberta Signorelli; RIBEIRO, Victoria Maria Brandt. Sistema Único de Saúde e a formação dos médicos: um diálogo possível? Interface - Comunicação, Saúde, Educação, Botucatu, v. 12, n. 24, p. 125-140, 2008.

CYRINO, Eliana Goldfarb; PEREIRA, Maria Lucia Torrales. Trabalhando com estratégias de ensino-aprendizado por descoberta na área da saúde: a problematização e a aprendizagem baseada em problemas. Cadernos de Saúde Pública, Rio de Janeiro, v. 20, n. 3, p. 780-788, 2008.

FERREIRA, Vitória Solange Coelho et al. Processo de trabalho do agente comunitário de saúde e a reestruturação produtiva. Cadernos de Saúde Pública, Rio de Janeiro, v. 25, n. 4, p. 898-906, 2009.

GONDIM, Sônia Maria Guedes. Grupos focais como técnica de investigação qualitativa: desafios metodológicos. 2002. Disponível em: <http://sites.ffclrp.usp.br/paideia/artigos/ 24/03.doc $>$. Acesso em: 20 jun. 2009.

CONSENSO BRASILEIRO DE EDUCAÇÃO EM ASMA, 1. Plano de Educação e Controle da Asma. Jornal de Pneumologia, São Paulo, v. 22, supl. 1, 1996.

IMPERATORI, Giceli; LOPES, Marta Julia Marques. Estratégias de intervenção na morbidade por causas externas: como atuam agentes comunitários de saúde? Saúde e Sociedade, São Paulo, v. 18, n. 1, p. 83-94, 2009.

LOPES, Sara Regina Souto et al. Potencialidades da educação permanente para a transformação das práticas de saúde. Comunicação, Ciências e Saúde, Brasília, v. 18, n. 2, p. 147-155, 2007.

LEONELLO, Valéria Marli; OLIVEIRA, Maria Amélia de Campos. Competências para ação educativa da enfermeira. Revista LatinoAmericana de Enfermagem [on line], Ribeirão Preto, v. 16, n. 2, 2008. Disponível em: <www.scielo.br/pdf/rlae/v16n2/pt_02.pdf>. Acesso em: 28 fev. 2012.
MACIEL, Marjorie Ester Dias et al. Educação em saúde na percepção de agentes comunitários de saúde. Cogitare Enfermagem, Porto Alegre, v. 14, n. 2, p. 340-345, 2009.

MELO, Gilberto; SANTOS, Regina Maria dos; TREZZA, Maria Cristina Soares Figueiredo. Entendimento e prática de ações educativas de profissionais do Programa Saúde da Família de São Sebastião-AL: detectando dificuldades. Revista Brasileira de Enfermagem, Brasília, v. 58, n. 3, p. 290-295, 2005.

MENDES, Isabel Amélia Costa et al. O referencial da educação popular na ação gerencial e de liderança do enfermeiro. Texto e Contexto Enfermagem, Florianópolis, v. 16, n. 2, p. 303-306, 2007.

MENDONÇA, Maria Helena Magalhães de. Agente comunitário de saúde: o ser, o saber, o fazer. Cadernos de Saúde Pública, Rio de Janeiro, v. 20, n. 5, p. 1433-1434, 2004.

MEYER, Dagmar E. Esterrmann et al. 'Você aprende. A gente ensina?' Interrogando relações entre educação e saúde desde a perspectiva da vulnerabilidade. Cadernos de Saúde Pública, Rio de Janeiro, v. 22, n. 6 , p. 1335-1342, 2006.

MIRANDA, Karla Corrêa; BARROSO, Maria Grasiela Teixeira. A contribuição de Paulo Freire à prática e educação crítica em enfermagem. Revista Latino-Americana de Enfermagem, Ribeirão Preto, v. 12, n. 4, p. 631-635, 2004.

MOURA, José Augusto Rubim de; CAMARGOS, Paulo Augusto Moreira; BLIC, Jacques de. Tratamento profilático da asma. Jornal de Pediatria, Rio de Janeiro, v. 78, supl. 2, p. 141-150, 2002.

NICOLETTO, Sônia Cristina Stefano et al. Pólos de Educação Permanente em Saúde: uma análise da vivência dos atores sociais no norte do Paraná. Interface - Comunicação, Saúde, Educação [on line], Botucatu, v. 13, n. 30, p. 209-219, 2008. 
PASCHOAL, Amarílis Schiavon; MANTOVANI, Maria de Fátima; MÉIER, Marineli Joaquim. Percepção da educação permanente, continuada e em serviço para enfermeiros de um hospital de ensino. Revista da Escola de Enfermagem da USP, São Paulo, v. 41, n. 3, p. 478-484, 2007.

PEREIRA, Adriana Lenho de Figueiredo. As tendências pedagógicas e a prática educativa nas ciências da saúde. Cadernos de Saúde Pública, Rio de Janeiro, v. 19, n. 5, p. 1527-1534, 2003.

PEREIRA, Audrey Vidal; VIEIRA, Ana Luiza Stiebler; AMÂNCIO FILHO, Antenor. Grupos de educação em saúde: aprendizagem permanente com pessoas soropositivas para o HIV. Trabalho, Educação e Saúde, Rio de Janeiro, v. 9, n. 1, p. 25-41, 2011.
SHIMIZU, Helena Eri; ROSALES, Carlos. As práticas desenvolvidas no Programa Saúde da Família contribuem para transformar o modelo de atenção à saúde? Revista Brasileira de Enfermagem, Brasília, v. 62, n. 3, p. 424-429, 2009.

SILVA, Joana Azevedo da; DALMASO, Ana Sílvia Whitaker. O agente comunitário de saúde e suas atribuições: os desafios para os processos de formação de recursos humanos em saúde. Interface - Comunicação, Saúde, Educação, Botucatu, v. 6, n. 10, p. 75-96, 2002.

VIEIRA, Jeorge Wagner da Conceição; SILVA, Anderson Aquiles; OLIVEIRA, Flávia Márcia. Conhecimento e impacto sobre o manejo das crises de pacientes portadores de asma. Revista Brasileira de Enfermagem, Brasília, v. 61, n. 6, p. 853-857, 2008.

Recebido em 15/07/2011

Aprovado em 30/09/2011 